\title{
Geospatial Techniques, a Superlative Method to Assess Urban Heat Island Intensity: The Case of Abuja Municipal, Nigeria
}

\author{
M. E. Awuh ${ }^{1 *}$, P. O. Japhets ${ }^{2}$, I. C. Enete ${ }^{2}$ \\ ${ }^{1}$ Department of Geography \& Planning, University of Bamenda (UBa), Bamenda, Cameroon \\ ${ }^{2}$ Department of Geography \& Meteorology, Nnamdi Azikiwe University (NAU), Awka, Nigeria \\ Email: *awuhekolok@yahoo.co.uk
}

How to cite this paper: Awuh, M.E., Japhets, P.O. and Enete, I.C. (2021) Geospatial Techniques, a Superlative Method to Assess Urban Heat Island Intensity: The Case of Abuja Municipal, Nigeria. Journal of Geographic Information System, 13, 52-64. https://doi.org/10.4236/igis.2021.131004

Received: January 4, 2021

Accepted: February 17, 2021

Published: February 20, 2021

Copyright $\odot 2021$ by author(s) and Scientific Research Publishing Inc. This work is licensed under the Creative Commons Attribution International License (CC BY 4.0).

http://creativecommons.org/licenses/by/4.0/

\begin{abstract}
Most cities around the world, including Abuja Municipal are being faced with an undesirable increased in air temperature. This is indicated by an increase in non-porous, non-evaporating, highly thermal conductive surfaces such as concrete and asphalt, which has replaced the vegetation biomass resulting to the formation of urban heat island. There is an increasing need for studies on the changing trend of UHI intensity in cities. This research employed geospatial techniques to determine the urban heat island intensity in Abuja Municipal. Temperature characteristics over twenty selected rural and urban locations in Abuja, FCT were derived from the satellite image of 1986, 2001 and 2016 using the "Extract Multi Values to Point" tool in ArcGIS 10.4. These transects pass over various landscapes with different environmental settings, with the aim of understanding the factors shaping the city's thermal landscape. The intervals of +15 years were deliberately chosen to ensure uniformity between the datasets. The results of this analysis indicate that UHII has been increasing, from 1986-2016, giving credence to the results of the spatial and temporal analysis of the land surface temperature, indicating the development phases had hit full stride. The different periods under study (1986, 2001 and 2016) were also tested using the student " $t$ " test to determine the significant difference in the land surface temperature values to acknowledge the presence of a substantial urban heat island within the study area. The result reveals the calculated " $t$ " values of 2.50, 3.34, 5.57 of 1986, 2001 and 2016 respectively, are higher than the critical value of " $\mathrm{t}$ " at 0.05 being 1.73 , thus, revealing the temperature differences between the urban and rural stations to be highly significant, indicating the presence of a strong urban heat island. Also, a slide difference in the temperature was observed with the Rubuchi and Karmajiji rural areas having higher temperature readings than their counter-
\end{abstract}


parts in the urban areas, Asokoro and Garki, with readings of $-0.4^{\circ} \mathrm{C}$ and $-1.3^{\circ} \mathrm{C}$. Since effectiveness of a surface in reducing daytime urban air temperatures depends strongly on the amount of heating avoided, the study recommends preserving and replicating greenery, light coloured facades as measures to reduce the effects of urban heat island.

\section{Keywords}

Geospatial Techniques, Abuja Municipal, UHII, Superlative Method

\section{Introduction}

Human activities alter the natural land covers which have resulted in changes in thermal capacities, albedo coefficient, heat conductivity, and moisture [1] [2] [3]. Urban land uses can cause the local air and surface temperatures to increase several degrees than the temperatures of the surrounding environment [4] [5]. This phenomenon is often referred to as an urban heat island (UHI), which has been documented since 1818 [6]. In many previous researches the occurrence of the UHI phenomenon was considered as one of the most important problems of overheating in urban areas [7] [8] [9]. The urban heat island intensity (UHII) is determined as the spatially averaged temperature difference between an urban and its surrounding rural area [10]. The adjective "rural" is being used to refer to areas of the non-urban or reference point [6].

The UHI can be identified by earth surface temperatures [10]. Several studies have used numerical models to investigate how the UHI evolves into summertime heat waves, and concluded that, heatwave amplifies urban-rural temperature differences at night and during the daytime [10] [11] [12] [13]. The Landsat TM data is one of the most widely used satellite images of LST retrieving because of its high resolution $(120 \mathrm{~m})$ and free download availability from the website of US Geological Survey (USGS), which has one thermal infrared (TIR) band [11] [12] [14]. Abuja municipal which is the federal capital territory of Nigeria has witnessed a large influx of people into the city, which has led to the emergence of satellite towns and smaller settlements to accommodate this increased populace [15]. This increase in the physical boundaries implies a corresponding loss of vegetation and land in the area thereby a direct impact on the micro-climate [15]. This study seeks to ascertain if there is a significant difference in the land surface temperature between the urban and the rural areas in Abuja municipal using twenty selected transects points. The authors declare that, this research was not sponsored by any financial institution, thus, there is no conflict of interest.

\section{Material and Method}

\subsection{Study Area}

The study area, Abuja Municipal Area Council, is situated between latitudes 
$8^{\circ} 37^{\prime} 41^{\prime \prime}$ and $9^{\circ} 9^{\prime} 15^{\prime \prime}$ north of the equator, and longitudes $7^{\circ} 3^{\prime} 55^{\prime \prime}$ and $7^{\circ} 34^{\prime}$ east of the Greenwich Meridian. Abuja Municipal, being the Capital City, covers an area of approximately $1456 \mathrm{~km}^{2}$. The area contains the following districts and satellite towns; Central Business District, Maitama, Asokoro, Wuse, Kubwa, Lugbe etc. as depicted in Figure 1.

The study area has a projected population of 3,564,126 persons, being the fourth densely inhabited area in Nigeria [16]. Under Koppen climate classification (Aw), the study area has a tropical wet and dry climate, experiences three weather conditions annually, which include a warm, humid rainy season and a scorching dry season with a brief interlude of harmattan associated with dust haze, intensified coldness and dryness in between the two. The study area records an annual rainfall of about $1631.7 \mathrm{~mm}$, highest within the FCC [17]. It records relative humidity in the dry season which goes as high as (20\%) in the afternoons at the northern high elevations and about (30\%) in the extreme south. During the rainy season, relative humidity rises as much as (50\%) [17] The dominant vegetation of the area is classified into these savannah types, park/grassy savannah, savannah woodland, and shrub savannah, with the grassy savannah being the most dominant class. The soil is basically alluvial and luvisols making it a fertile ground for agriculture and vegetation growth. Abuja has witnessed a large influx of people into the city, this unprecedented increase has led to the emergence of satellite towns and smaller settlements to accommodate this increased populace [16]. This increase in the physical boundaries implies a corresponding loss of vegetation and land in the area thereby a direct impact on the micro-climate.

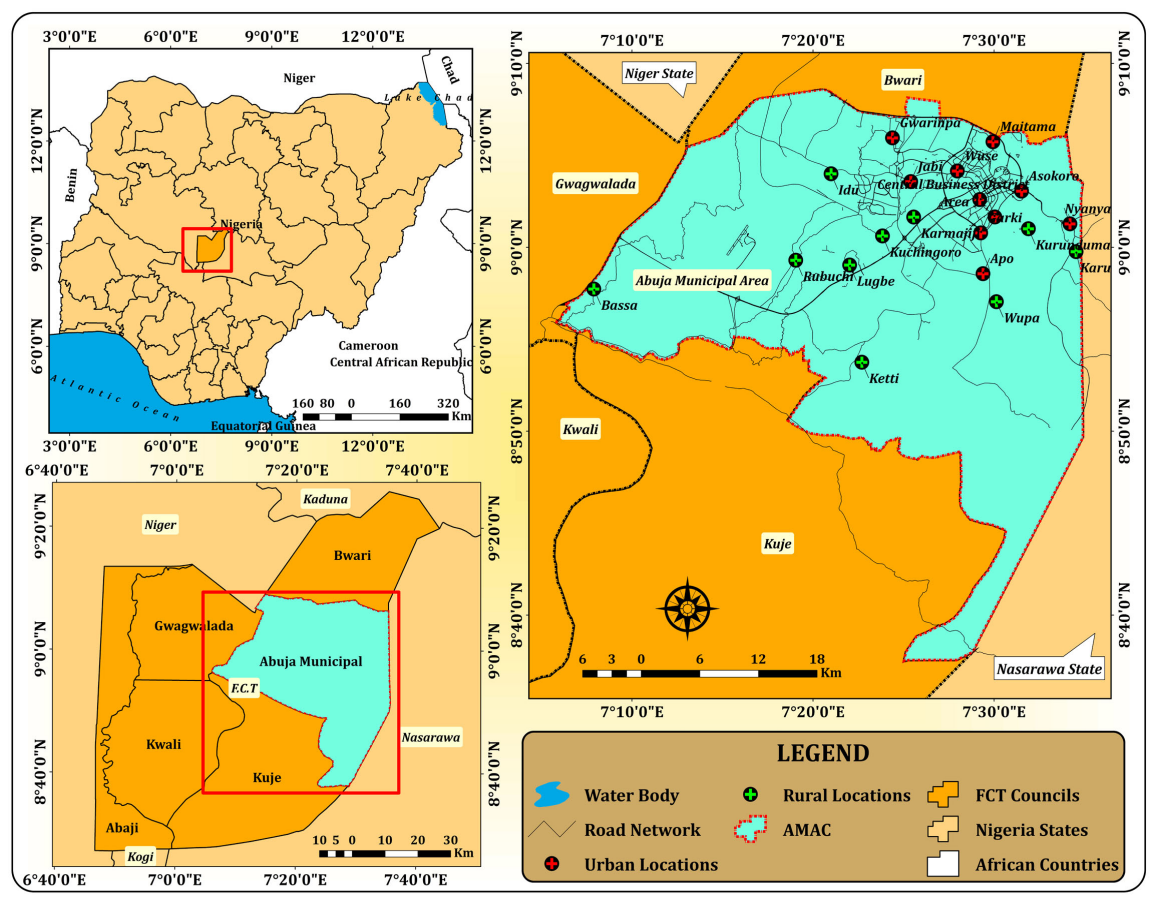

Figure 1. Map of FCT showing AMAC, inset: Map of Nigeria showing FCT. 


\subsection{Image and Pre-Processing}

The LANDSAT data were downloaded from USGS Earth Explorer, in 2017. The Thematic Mapper (TM) images were downloaded on $26^{\text {th }}$ Dec., 1986. The Enhance Thematic Mapper plus (ETM+) images were downloaded on $27^{\text {th }}$ Dec., 2001 and the Operational Land Imager (OLI) on $28^{\text {th }}$ Dec., 2016. The intervals of +15 years were deliberately chosen by the researcher to ensure uniformity between the datasets. The Landsat satellite data have $30 \mathrm{~m}$ spatial resolutions, the TM/ETM+ images have spectral range of $0.45-2.35$ micrometer $(\mu \mathrm{m})$ with bands 1 to 7 and 8 respectively while the Operational Land Imager (OLI) extends to band 12. They were used for image classification and LST extraction. The administrative maps of Nigeria containing states and LGA's were gotten from the National Space Research and Development Agency (NASRDA). It is a projected vector shape file, that was used to specify the boundary of the study area.

\subsection{Retrieval of Land Surface Temperature (LST) from LANDSAT Images}

The mono-window algorithm method is adopted to retrieve the LST from the imageries selected for this study. The Landsat-5 TM thermal bands 6 (10.40 $12.50 \mu \mathrm{m})$, ETM+ bands $6 \mathrm{~L}(10.4-12.5 \mu \mathrm{m})$ and TIRS 10 and $11(10.60-11.19$ $\mu \mathrm{m}$ ) have a spatial resolution of $30 \mathrm{~m}$ respectively which is considered suitable as shown by many literatures for capturing the multifaceted intra-urban temperature differences thus making it effective for urban climate analysis. The Landsat ETM+ sensor, images of the thermal band are taken twice: one in the low-gain mode (band 6L) and the other in the high-gain mode (band 6H). Band 6L is used to image surfaces with high brightness, band $6 \mathrm{H}$ is for low brightness. Band $6 \mathrm{~L}$ was used in this study, due to errors contained in the $6 \mathrm{H}$ band. Consequently, the LANDSAT thermal bands were used to retrieve LST over the study area for the three different periods (1986, 2001, and 2016) using various procedures which range from radiometric calibration, conversion of DN to radiance, correction for atmospheric absorption, re-emission and surface emissivity which has been used in [18] as described below:

Conversion of Digital Numbers (DN) of the bands to Spectral Radiance [18]

$$
L_{\lambda}=\left\lfloor\frac{L_{\mathrm{MAX}}-L_{\mathrm{MIN}}}{Q_{\mathrm{Calmax}}-Q_{\mathrm{CALMIN}}}\right\rfloor \times(\mathrm{DN}-1)+L_{\mathrm{MIN}}
$$

where:

$L_{\mathrm{MAX}}=$ the spectral radiance that is scaled to $Q_{\mathrm{CALMAX}}$ in $\mathrm{W} /\left(\mathrm{m}^{2} \cdot \mathrm{sr} \cdot \mu \mathrm{m}\right) L_{\mathrm{MIN}}=$ the spectral radiance that is scaled to $Q_{\mathrm{CALMIN}}$ in $\mathrm{W} /\left(\mathrm{m}^{2} \cdot \mathrm{sr} \cdot \mu \mathrm{m}\right) Q_{\mathrm{CALMAX}}=$ the maximum quantized calibrated pixel value (corresponding to $L_{\mathrm{MAX}}$ ) in $\mathrm{DN}=255$ $Q_{\text {CALMIN }}=$ the minimum quantized calibrated pixel value (corresponding to $L_{\text {MIN }}$ ) in $\mathrm{DN}=1$.

Conversion from Spectral Radiance to At-Satellite Brightness Temperature [18] 


$$
T=\frac{K_{2}}{\ln \left(\frac{K_{1}}{L_{\lambda}}+1\right)}-273.15
$$

where:

$T=$ At-satellite brightness temperature, $L_{l}=$ Spectral radiance (gotten from Equations (1) and (2)), $K_{1}=$ Band specific thermal conversion constant from the metadata, $\mathrm{x}$ is the thermal band number, $K_{2}=$ Band specific thermal conversion constant from the metadata, $-273.15=$ Constant for conversion from Kelvin to Degrees Celsius as shown in [16].

Correcting for Land Surface Emissivity (LSE) [18]

The temperature values obtained using Equation (2) are reference to a blackbody. Therefore, corrections for spectral emissivity $(\varepsilon)$ became necessary according to the nature of land cover (Equation (3))

$$
e=0.004 P_{V}+0.986
$$

where, $e=$ Land Surface Emissivity, $0.004 \& 0.986=$ Constants for emissivity estimation, $P_{V}=$ Proportion of vegetation [16] given by the equation

$$
P_{V}\left(\frac{\mathrm{NDVI}^{-\mathrm{NDVI}_{\text {min }}}}{\mathrm{NDVI}_{\text {max }}-\mathrm{NDVI}_{\text {min }}}\right)
$$

where, NDVI = Normalized Differential Vegetation Index as computed with

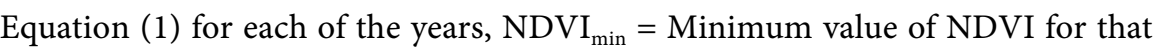

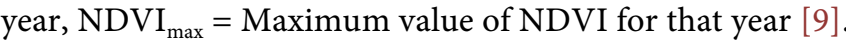

Estimation of the Land Surface Temperature [18]

$$
\mathrm{LST}=\frac{B_{T}}{1+W} \times \frac{B_{T}}{P} \times \ln \left(\sum\right)
$$

where: LST $=$ Land Surface Temperature, $B_{T}=$ At-satellite brightness temperature, $W=$ Wavelength of emitted radiance $(\mu \mathrm{m})[16]$ given as:

$$
P=h \times \frac{c}{S}\left(1.438 \times 10^{-2} \mathrm{~m} \cdot \mathrm{K}\right)=14380
$$

$h=$ Planck's constant $\left(6.626 \times 10^{-34} \mathrm{~J} \cdot \mathrm{s}\right), S=$ Boltzmann constant $\left(1.38 \times 10^{-23}\right.$ $\mathrm{J} / \mathrm{K}), C=$ Velocity of light $\left(2.998 \times 10^{8} \mathrm{~m} / \mathrm{s}\right), e=\mathrm{LSE}$.

\subsection{Urban Heat Island (UHI) Assessment}

Points representing ten rural and ten urban areas in Abuja Municipal were generated, and the temperature readings for each location were extracted using the "Extract Multi Values to Point" tool in ArcGIS 10.4. Then, the urban heat island was assessed using the equation:

$$
\mathrm{UHI}=T_{U}-T_{R}
$$

where:

$\mathrm{UHI}=$ Urban Heat Intensity;

$T_{U}=$ Temperature at urban station;

$T_{R}=$ Temperature at rural station. 


\subsection{Statistical Analysis}

Students " $\mathrm{t}$ " Test was carried out to determine the significant difference between the urban and rural temperature values and test of hypothesis.

\section{Student's T-Test}

The $t$-test is used to determine if two sets of data are significantly different from each other. In this study, it is used to test the hypothesis and determine the significance of the difference between urban/rural temperatures. The independent unpaired samples t-test was implemented due to the independent and identically distributed samples of the rural and urban temperature values. The $t$ statistic to test if the means are significantly different can be calculated as follows:

$$
t=\frac{\bar{X}_{1}-\bar{X}_{2}}{\sqrt{\frac{S_{1}^{2}}{N_{1}}}+\frac{S_{2}^{2}}{N_{2}}}
$$

where: $S_{1}$ and $S_{2}=$ Standard deviation for $N, N=$ Number of observations,

$\bar{X}_{1}-\bar{X}_{2}=$ Standard error of the difference between the two means.

For significance testing, the degree of freedom for this test is given by:

$N_{1}+N_{2}-2$, where $N=$ Number of observations in each group.

\section{Result Presentation and Discussion}

\subsection{Determination of Urban Heat Island Intensity (UHII)}

Urban areas tend to have higher air temperatures than surrounding rural areas as a result of vegetation cover being replaced by non-porous, non-evaporating, highly thermal conductive surfaces such as concrete and asphalt [19] [20]. The UHII is determined as the spatially averaged temperature difference between an urban and its surrounding rural area [11]. In order to determine urban heat island intensity in Abuja Municipal, twenty transects representing urban and rural areas located in the area were chosen using satellite derived images of 1986, 2001 and 2016 respectively (Figure 2). These transects pass over various landscapes with different environmental settings, an inquiry into the Urban Heat Island characteristics of the profile will help to understand the factors shaping the city's thermal landscape. The urban and rural transects selected are displayed in Table 1 .

\subsection{Average Temperature Difference in 1986, 2001 and 2016}

The temperature difference between the ten urban and ten rural stations based on the results of satellite derived imagery of 1986 (Figure 3) is displayed in Table 2.

Tables 2-5 and Figure 3 divulge the temperature characteristics over twenty selected locations in Abuja, FCT as derived from the satellite image of 1986, 2001 and 2016 (Figure 2). As revealed by the satellite derived image (Figure 2), a great variation was observed in the temperature distribution of the selected 


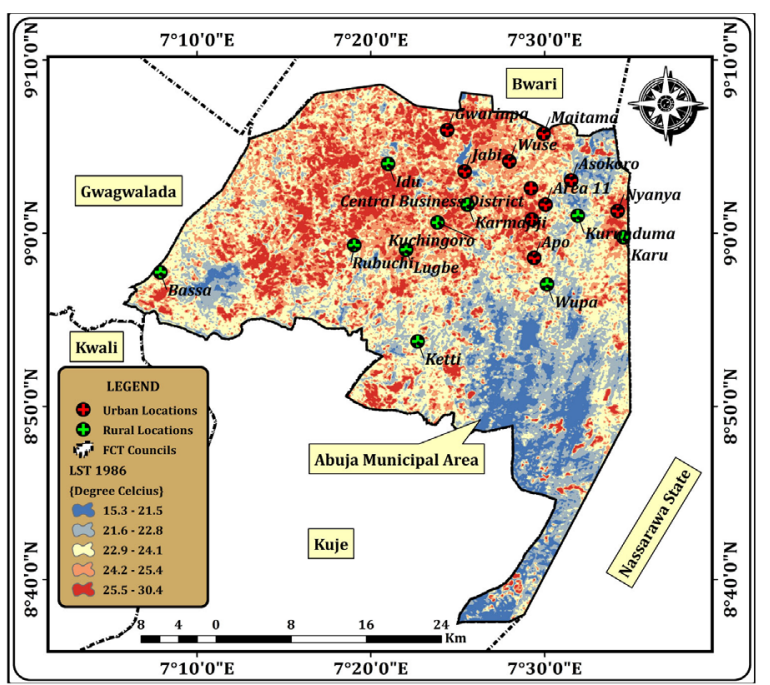

(a)

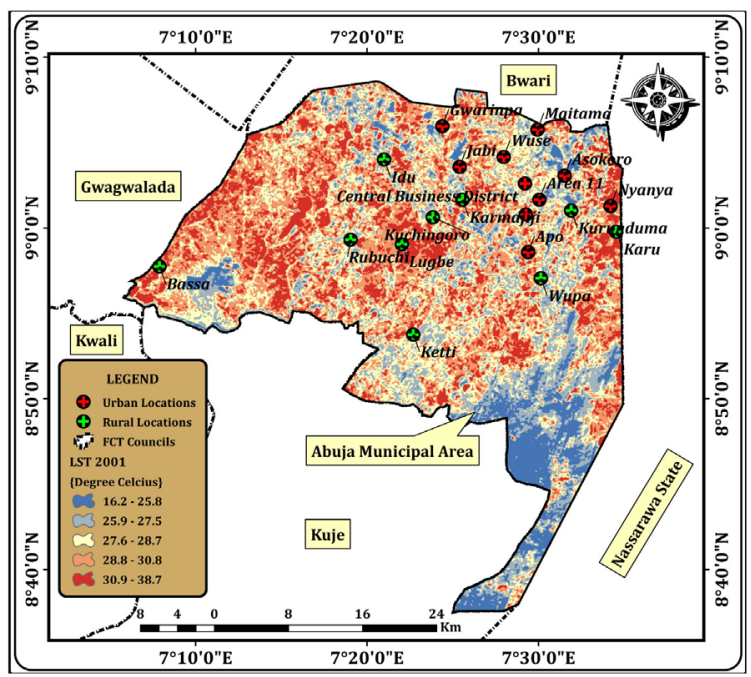

(b)

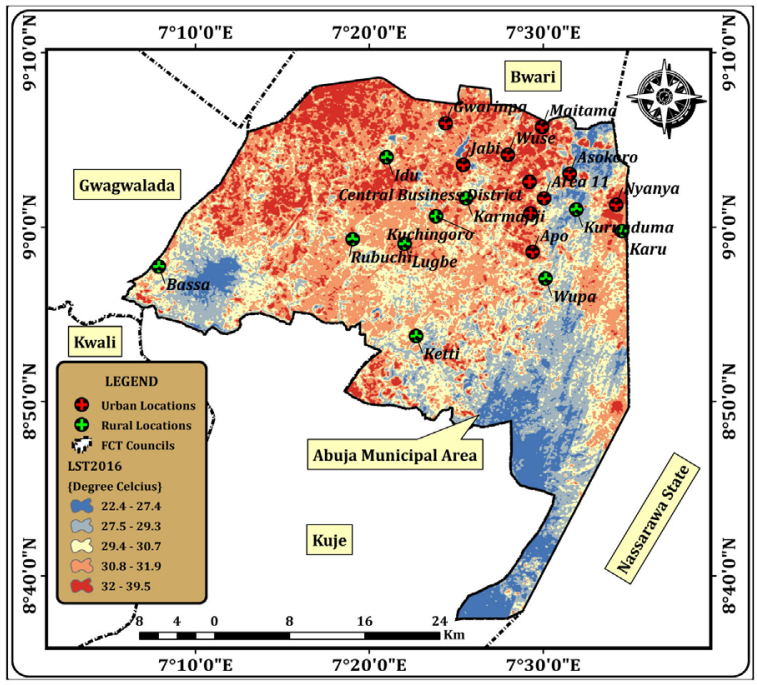

(c)

Figure 2. LST distribution over Abuja based in 1986 (a); 2001 (b) and 2016 (c). 
Table 1. Points representing urban and rural areas.

\begin{tabular}{cc}
\hline URBAN & RURAL \\
Apo & Bassa \\
Area 11 & Lugbe \\
Asokoro & Rubuchi \\
Central Business District & Wupa \\
Garki & Karmajiji \\
Gwarinpa & Kuchingoro \\
Jabi & Ketti \\
Maitama & Kurunduma \\
Nyanya & Karu \\
Wuse & Idu \\
\hline
\end{tabular}

Table 2. Mean temperature and UHI intensity for 1986.

\begin{tabular}{ccccc}
\hline URBAN & Mean Temp $\left({ }^{\circ} \mathrm{C}\right)$ & RURAL & Mean Temp $\left({ }^{\circ} \mathrm{C}\right)$ & $\Delta \mathrm{Tu}-\mathrm{r}\left({ }^{\circ} \mathrm{C}\right)$ \\
\hline Apo & 24.6 & Bassa & 24.1 & 0.4 \\
Area 11 & 26.3 & Lugbe & 25.4 & 0.8 \\
Asokoro & 25.0 & Rubuchi & 25.4 & -0.4 \\
Central Business District & 25.0 & Wupa & 24.1 & 0.9 \\
Garki & 24.6 & Karmajiji & 25.8 & -1.3 \\
Gwarinpa & 26.7 & Kuchingoro & 24.1 & 2.5 \\
Jabi & 24.6 & Ketti & 22.8 & 1.7 \\
Maitama & 25.4 & Kurunduma & 21.5 & 3.9 \\
Nyanya & 25.8 & Karu & 24.1 & 1.7 \\
Wuse & 24.1 & Idu & 24.1 & 0.0 \\
\hline
\end{tabular}

Table 3. Mean temperature and UHII for 2001.

\begin{tabular}{ccccc}
\hline URBAN & Mean Temp $\left({ }^{\circ} \mathrm{C}\right)$ & RURAL & Mean Temp $\left({ }^{\circ} \mathrm{C}\right)$ & $\Delta \mathrm{Tu}-\mathrm{r}\left({ }^{\circ} \mathrm{C}\right)$ \\
\hline Apo & 30.4 & Bassa & 28.8 & 1.6 \\
Area 11 & 28.8 & Lugbe & 30.0 & -1.2 \\
Asokoro & 30.8 & Rubuchi & 29.2 & 1.6 \\
Central Business District & 32.0 & Wupa & 30.0 & 2.0 \\
Garki & 29.2 & Karmajiji & 30.8 & -1.6 \\
Gwarinpa & 32.8 & Kuchingoro & 29.2 & 3.7 \\
Jabi & 31.2 & Ketti & 28.8 & 2.5 \\
Maitama & 32.0 & Kurunduma & 25.0 & 7.0 \\
Nyanya & 31.6 & Karu & 29.6 & 2.0 \\
Wuse & 32.4 & Idu & 27.9 & 4.5 \\
\hline
\end{tabular}




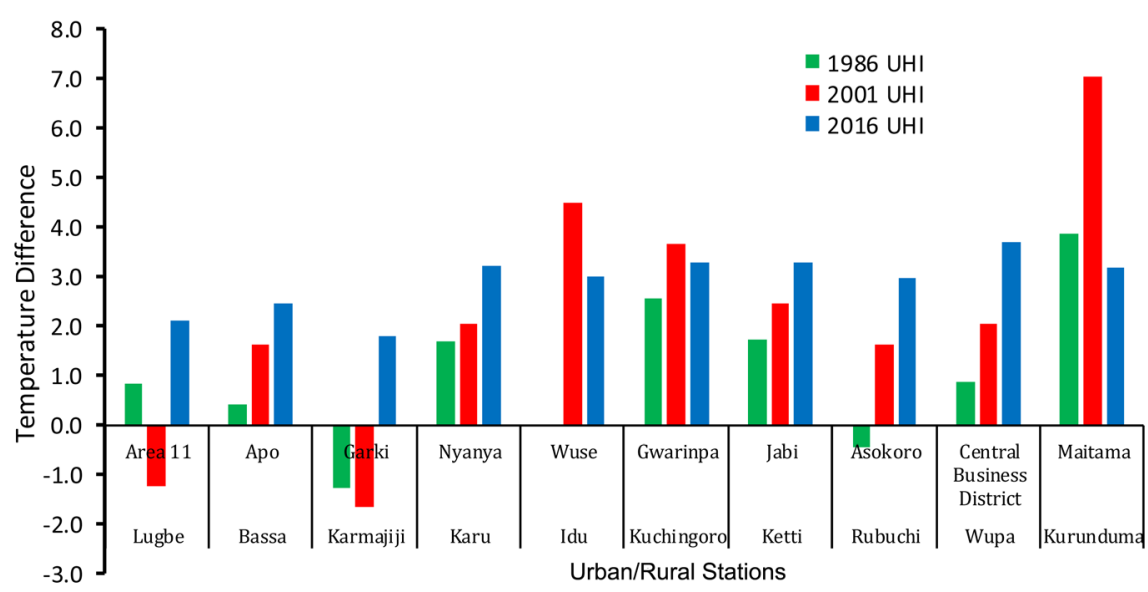

Figure 3. UHI intensity at different locations across the study area.

Table 4. Mean temperature and UHI intensity for 2016.

\begin{tabular}{ccccc}
\hline URBAN & Mean Temp $\left({ }^{\circ} \mathrm{C}\right)$ & RURAL & Mean Temp $\left({ }^{\circ} \mathrm{C}\right)$ & $\Delta$ Tu-r $\left({ }^{\circ} \mathrm{C}\right)$ \\
\hline Apo & 34.3 & Bassa & 31.8 & 2.5 \\
Area 11 & 34.5 & Lugbe & 32.3 & 2.1 \\
Asokoro & 32.3 & Rubuchi & 29.3 & 3.0 \\
Central Business District & 32.1 & Wupa & 28.4 & 3.7 \\
Garki & 33.6 & Karmajiji & 31.8 & 1.8 \\
Gwarinpa & 33.4 & Kuchingoro & 30.1 & 3.3 \\
Jabi & 32.9 & Ketti & 29.7 & 3.3 \\
Maitama & 31.3 & Kurunduma & 28.1 & 3.2 \\
Nyanya & 33.6 & Karu & 30.3 & 3.2 \\
Wuse & 33.5 & Idu & 30.5 & 3.0 \\
\hline
\end{tabular}

Table 5. Student " $t$ " test summary for 1986.

\begin{tabular}{cccc}
\hline & Variable 1 & Variable 2 \\
\hline Mean & 25.19964 & & 24.17388 \\
Variance & 0.687705 & & 1.614725 \\
Observations & 10 & 10 & \\
Degree of Freedom & & 1.73 & \\
T crit & & 0.05 & \\
Alpha Value & & 2.5 & \\
T calc & &
\end{tabular}

locations for the years under study. Table 2 shows the average surface temperature and the differences between the 10 rural and urban points selected for 1986 . In 1986, Gwarinpa was the urban area was associated with the highest temperature value of $26.7^{\circ} \mathrm{C}$ and Kurunduma the rural area associated with the lowest temperature with a temperature value of $21.5^{\circ} \mathrm{C}$, the highest difference was ob- 
served between Maitama urban area and Kurunduma rural area with a temperature difference of $3.9^{\circ} \mathrm{C}$. The findings revealed the average temperature difference (UHI) to be $1.0^{\circ} \mathrm{C}$ (Table 2).

For 2001, each of the locations experienced an increase in mean temperature with Gwarinpa and Kurunduma being attributed with the highest and lowest temperature of the year, with a temperature of $32.8^{\circ} \mathrm{C}$ and $25.0^{\circ} \mathrm{C}$ (Table 3). furthermore, though Gwarinpa urban area and Kurunduma rural area recorded the mean highest and lowest temperature, the area with the highest urban heat island intensity was between Maitama urban area and Kurunduma rural area with a temperature difference of $7.0^{\circ} \mathrm{C}$ (Figure 3 ).

Looking at the temperature characteristics in 2016 (Table 4), there was also a significant increase in mean average temperature compared to 1986 and 2001 respectively. The highest temperature was observed in Area $11\left(34.5^{\circ} \mathrm{C}\right)$, an urban area, the lowest temperature was observed in Kurunduma $\left(28.1^{\circ} \mathrm{C}\right)$. The highest temperature difference of $3.7^{\circ} \mathrm{C}$ in 2016 was observed between the central business district (CBD) and Wupa rural area (Table 4).

\subsection{Hypothesis Testing}

The hypothesis is stated as thus: "There is no significant difference in land surface temperature between the urban and rural stations selected." The variables considered are the independent and equally the temperature distributed values of each of these locations. The different periods under study (1986, 2001 and 2016) were tested to determine the significant difference in the land surface temperature values to acknowledge the presence of a substantial UHI within the study area (Tables 5-7).

Table 6. Student " $t$ " test summary for 2001

\begin{tabular}{cccc}
\hline & Variable 1 & & Variable 2 \\
\hline Mean & 31.12497 & & 28.91495 \\
Variance & 1.82937 & & 2.54383 \\
Observations & 10 & & 10 \\
Degree of Freedom & & 18 & \\
T crit & & 1.73 & \\
Alpha Value & & 0.05 & \\
T calc & & 3.34 & \\
\hline
\end{tabular}

Table 7. Student "t" test summary for 2016.

\begin{tabular}{cccc}
\hline & Variable 1 & & Variable 2 \\
\hline Mean & 33.14379 & & 30.24322 \\
Variance & 0.98566 & & 2.0553 \\
Observations & 10 & 18 & 10 \\
Degree of Freedom & & 1.73 & \\
T crit & & 0.05 & \\
Alpha Value & & 5.576 & \\
T calc & & & \\
\hline
\end{tabular}


Table 5 represents the student " $\mathrm{t}$ " test summary of 1986 . From the student " $\mathrm{t}$ " distribution table (Table 5), the critical value of " $t$ " at 0.05 is 1.73 . Since the calculated " $\mathrm{t}$ " value of 2.50 is higher than the critical value, the null hypothesis is rejected for 1986, thus, inferring a significant temperature difference between the urban and rural stations, indicating the presence of an urban heat island. Similarly, a critical value of 1.73 was observed in 2001 (Table 6). Since the calculated " $t$ " value of 3.34 is higher than the critical value, the null hypothesis is rejected for 2001, thus, inferring a significant temperature difference between the urban and rural stations, indicating the presence of an urban heat island. The same trend was observed in 2016 as divulged in Table 7. The result as seen in Table 7 reveals the critical value of " $t$ " at 0.05 to be 1.73 . Since the calculated " $\mathrm{t}$ " value of 5.57 is higher than the critical value, the null hypothesis is rejected for 2016 as well, thus, indicating a significant temperature difference between the urban and rural stations, indicating the presence of an urban heat island.

\subsection{Discussion of Findings}

The findings of this study reveal an increase in the surface temperature over the study area, which has been attributed to increased impervious surfaces, and loss of vegetative cover. During the study period, the mean land surface temperature increased by $4.9^{\circ} \mathrm{C}$ from $23.5^{\circ} \mathrm{C}$ to $28.4^{\circ} \mathrm{C}$, an increase that was due to high level of urbanization that went on during that period [15]. In 1986, the average temperature difference of $1.0^{\circ} \mathrm{C}$ was observed between the urban areas and rural areas. The temperature differences are a major pointer to the low level of built up areas in the study area. By 2001, the urban areas gained significant development which caused loss of vegetative cover which consequently led to significant surface temperature increase of $2.2^{\circ} \mathrm{C}$ in 2001 compared to 1986 . Thus, an indicator that by this time, the development phases had hit full stride. It was also observed that some rural areas such as Rubuchi and Karmajiji had higher temperature readings than their counterparts in the urban areas (Asokoro and Garki) with readings of $-0.4^{\circ} \mathrm{C}$ and $-1.3^{\circ} \mathrm{C}$. The highest difference observed between some rural areas can be attributed to the increase in spatial extent due to the influx of migrants [15]. Increase in the average temperature difference of $2.9^{\circ} \mathrm{C}$ by 2016 has been pointed to the presence of a very strong urban heat island.

\section{Conclusion}

This study adopted geospatial techniques in assessing the spatiotemporal variation of the surface urban heat intensity in Abuja Municipal, FCT from 1986 to 2016. Based on the recording images of 1986 to 2016, the result reveals the calculated " $t$ " values of 2.50, 3.34, 5.57 of 1986, 2001 and 2016 respectively, are higher than the critical value of " $\mathrm{t}$ " at 0.05 being 1.73 , thus, revealing a highly significant temperature difference between the urban and rural stations, indicating the presence of a strong urban heat island. 


\section{Conflicts of Interest}

The authors declare no conflicts of interest regarding the publication of this paper.

\section{References}

[1] Reisi, M., Ahmadi Nadoushan, M. and Aye, L. (2019) Remote Sensing for Urban Heat and Cool Islands Evaluation in Semi-Arid Areas. Global Journal of Environmental Science and Management, 5, 319-330.

[2] Li, H., Harvey, J. and Kendall, A. (2013) Field Measurement of Albedo for Different Land Cover Materials and Effects on Thermal Performance. Building and Environment, 59, 536-546. https://doi.org/10.1016/j.buildenv.2012.10.014

[3] Odunuga, S. and Badru, G. (205) Landcover Change, Land Surface Temperature, Surface Albedo and Topography in the Plateau Region of North-Central Nigeria. Land, 4, 300-324. https://doi.org/10.3390/land4020300

[4] Streutker, D.R. (2003) Satellite-Measured Growth of the Urban Heat Island of Houston, Texas. Remote Sensing of Environment, 85, 282-289.

https://doi.org/10.1016/S0034-4257(03)00007-5

[5] Wang, X. and Prigent, C. (2020) Comparisons of Diurnal Variations of Land Surface Temperatures from Numerical Weather Prediction Analyses, Infrared Satellite Estimates and in Situ Measurements. Remote Sensing, 12, 583.

https://doi.org/10.3390/rs12030583

[6] Howard, L. (1818) The Climate of London. https://www.urban-climate.org/documents/LukeHoward_Climate-of-London-V1.p df

[7] Li, Y.Y., Zhang, H. and Kainz, W. (2012) Monitoring Patterns of Urban Heat Islands of the Fast-Growing Shanghai Metropolis, China: Using Time-Series of Landsat TM/ETM+ Data. International Journal of Applied Earth Observation and Geoinformation, 19, 127-138. https://doi.org/10.1016/j.jag.2012.05.001

[8] Enete, I.C., Awuh, M.E. and Ikekpeazu, F. (2014) Assessment of Urban Heat Island (UHI) Situation in Douala Metropolis, Cameroon. Journal of Geography and Earth Sciences, 2, 55-57. https://doi.org/10.11648/j.ijepp.20140201.15

[9] Umar, U.M. and Kumar, J.S. (2014) Spatial and Temporal Changes of Urban Heat Island in Kano Metropolis, Nigeria. International Journal of Research in Engineering, Science and Technologies, 1, 1-9.

[10] Aris, A., Syaf, H., Yusuf, D.N. and Nurgiantoro (2019) Analysis of Urban Heat Island Intensity Using Multi Temporal Landsat Data; Case Study of Kendari City, Indonesia. IOP Conference Series: Earth and Environmental Science, 389, Article ID: 012002. https://doi.org/10.1088/1755-1315/389/1/012002

[11] Dousset, B. and Gourmelon, F. (2003) Satellite Multi-Sensor Data Analysis of Urban Surface Temperatures and Landcover. ISPRS Journal of Photogrammetry and Remote Sensing, 58, 43-54. https://doi.org/10.1016/S0924-2716(03)00016-9

[12] Sun, Q., Tan, J. and Xu, Y. (2010) An ERDAS Image Processing Method for Retrieving LST and Describing Urban Heat Evolution: A Case Study in the Pearl River Delta Region in South China. Environmental Earth Sciences, 59, 1047-1055.

https://doi.org/10.1007/s12665-009-0096-3

[13] Fu, P. and Weng, Q. (2017) Responses of Urban Heat Island in Atlanta to Different Land-Use Scenarios. Theoretical and Applied Climatology, 133, 1-13.

https://doi.org/10.1007/s00704-017-2160-3 
[14] Awuh, M.E., Officha, M.C., Okolie, A.O. and Enete, I.C. (2018) A Remote Sensing Analysis of the Temporal and Spatial Changes of Land Surface Temperature in Calabar Metropolis, Nigeria. Journal of Geographic Information System, 10, 562-572. https://doi.org/10.4236/jgis.2018.105030

[15] Awuh, M.E., Japhets, P.O., Officha, M.C., Okolie, A.O. and Enete, I.C. (2019) A Correlation Analysis of the Relationship between Land Use and Land Cover/Land Surface Temperature in Abuja Municipal, FCT, Nigeria. Journal of Geographic Information System, 11, 44-55. https://doi.org/10.4236/jgis.2019.111004

[16] National Population Commission (NPC) Nigeria (2006) Population Census of the Federal Republic of Nigeria: Analytical Report at the National Level, Lagos.

[17] NIMET (2016) Nigerians Concern Over Increase in Temperature. NOI Polls, Abuja.

[18] Awuh, M.E., Japhets, P.O., Officha, M.C., Okolie, A.O. and Enete, I.C. (2019) A Correlation Analysis of the Relationship between Land Use and Land Cover/Land Surface Temperature in Abuja Municipal, FCT, Nigeria. Journal of Geographic Information System, 11, 44-55. https://doi.org/10.4236/jgis.2019.111004

[19] Enete, I.C., Awuh, M.E. and Ikekpeazu, F.O. (2014) Assessment of Urban Heat Island (UHI) Situation in Douala Metropolis, Cameroon. Journal of Geography and Earth Sciences.

[20] Kaya, S., Karaca, M., Basar, U.G., Seker, D.Z. and Weng, D. (2012) Assessment of Urban Heat Islands Using Remotely Sensed Data. Ekoloji, 21, 107-113.

https://doi.org/10.5053/ekoloji.2012.8412 